\title{
Students' misconceptions about light in Algeria
}

D. Blizak, F. Chafiqi, D. Kendil

D. Blizak, F. Chafiqi, D. Kendil, "Students' misconceptions about light in Algeria," Proc. SPIE 9666, 11th Education and Training in Optics and Photonics Conference, 96661F (5 June 2009); doi: 10.1117/12.2207972

Event: Eleventh International Topical Meeting on Education and Training in Optics and Photonics, 2009, St. Asaph, United Kingdom 


\title{
Students Misconceptions about Light in Algeria
}

\author{
Blizak. $D^{1}$, Chafiqi. $F^{2}$, Kendil. $D^{3}$ \\ ${ }^{1}$ Faculté des Sciences, Université UMBB, Boumerdès, ALGERIA \\ ${ }^{2}$ ENS de Marrakech, Marrakech, MAROC. \\ ${ }^{3}$ ENS de Kouba, ALGER, ALGERIA
}

\begin{abstract}
Physics education research has shown that students have difficulties in learning essential optics concepts.

Therefore, in this present work we deal with student's conceptions in geometrical optics field. Our objective is to show the Algerian students misconceptions. We proposed to 246 students in first year university (aged 18-21) a closed questionnaire where most of its questions were already used by other researchers. The misunderstandings identified were compared with those in literature.

The results show that our students have the same misconceptions, related to the propagation of the light, the vision, the refraction and the reflexion, as the students in other countries (Andersson, Çiğdem ŞAHIN, Galili, Goldberg, Viennot,...).

We investigate new students "misconception" concerning the propagation of the light in the vacuum.
\end{abstract}

Misconception, Geometrical optics

\section{KEYWORDS}

\section{1, INTRODUCTIONI}

Light is an essential feature of everyday life. It is a key component of many modern technologies and is used as the primary tool in many sciences ranging from astronomy to zoology. Without some familiarity with the properties of light, students are not expected to fully grasp modern science.

The field of optics is a complex area for the students and many studies ha shown students' difficulties in learning optics see for example (Guesne 1985; Galili, Bendall and al. 1993; Galili and Hazan 2000; Tao 2004). The greatest number of these studies is concerns geometrical optics at the primary and secondary school.

There exists important evidence on the fact that the students at the university often have the same conceptual difficulties and of reasoning about optics that those largely divided by younger pupils (McDermott and Al, 1996). However, the studies at university level have been relatively rare. That is why we have chosen this level in our studies.

A lot of data about conceptions and representations regarding the phenomena of physics have been accumulated.

For Tiberghien ( 1997) A conception is seen as a hypothetical set of statements, skills, procedures attribute to one or more students in order to account for students' behaviour in a set of given situations. Other studies (eg: Goldberg \& McDermott, 1983) concluded that students did not use concepts systematically, and the particular situation determines the conception that is relevant. Many student conceptions were misconceptions and that these misconceptions were difficult to change through regular instruction.

Students come to science classes with opinions and intuitions about physical phenomena derived from prior learning, either in the classroom or from their interaction with the physical and social world (Bransford et al., 1999). Furthermore, these beliefs or opinions are sometimes different from the scientifically accepted ideas presented in the classroom.

Terms such as misconceptions, preconceptions, alternative frameworks, children's science, naive conceptions and so forth; are used to describe such beliefs (Pınarbaşı and Canpolat, 2003). 
Arons (1990), for example, prefers 'preconceptions'. He argues that the misconception is to be removed through asserting the correct notion. Viennot (1979) prefers 'intuitive notions' that reflect vagueness in student ideas rather than ideas which are well articulated. HUBBER (2005) uses 'alternative conceptions' for student's conceptions after teaching.

In the present paper we prefer using the word "misconception". It may be an appropriate term to use if only because the student may be judged right or wrong, although a misconception can be utilized as a "teaching aid'(Stuart Rowlands, 2007). Also for the reason that, Misconceptions are produced when people integrate new information, learnt at school, with previously held information resulting in the new knowledge being reinterpreted to correspond with everyday experiences (Duit, 2002; Duit, 2006). Vygotsky (1997) referred to the possibility that even if adults have successfully developed scientific concepts, their earlier everyday concepts may survive alongside.

About the main features of misconceptions research carried out some findings (Duit, and Al, 2003, Driver, 1989; Mortimer, 1995; Eve Kikas, 2003 ):

- Misconceptions of students in different countries and region are frequently similar to each other;

- Students' misconceptions are often strongly held, difficult to change through regular instruction;

- Culture, religion and language can cause the formation of some misconceptions;

- Misconceptions and the scientists' explanations can be used together in interpreting scientific phenomena;

- Misconceptions may develop after a formal teaching.

For better learning and understanding of scientific concepts, it has been recommended that before the beginning of the instruction, the students' misconceptions should be taken into account by teachers (Smith and Al., 1993).It must be interesting to take in consideration the misconceptions about light to elaborate a new teaching strategies because the traditional teaching strategies employed were not always successful in changing these conceptions.

In light of the studies and ideas outlined above, this study aims to reveal university students' misconceptions in Algeria about optics phenomena. Therefore, questions to be sought for the responses are:

1. 1. What are the misconceptions of Algerian first year university students about optics phenomena?

2. Are there any differences between students' misconception about light in Algeria and other countries?

3. Are there any changes in students' misconceptions after 30 years of research about light and optical phenomena conceptions?

\section{2, AN OVERVIEW OF PREVIOUS RESEARCH STUDENT'S MISCONCEPTIONS OF LIGHT}

Many studies have sought student's views and knowledge about light, vision and optics phenomena at different ages, grades and different countries during the past 30 years (Pfundt and Duit 1994, Galili, I. and A. Hazan 2000, Goldberg and McDermott (1983). The Studies of postinstruction students have revealed a persistence of student's misconceptions even after formal learning of optics.

We present here only the student's misconception at the university level before instruction and at secondary level after studying optics.

\subsection{Light propagation}

In a study by (Langley, Ronen et al. 1997), students' preconceptions were tested and they found that students didn't indicate direction in their representation of light.

Significant number of students in the Western Australian study believed that the distance light travels is depends on its energy. (Fetherstonhaugh 1990).

Goldberg and McDermott (1987) established that the students at the university designs such as a luminous object which has a determined form, sends parallel rays. That the rays are parallel implies obligatorily that this is the privileged direction; and it is generally a horizontal direction.

In physics, Shadows are formed when light is stopped by objects, but students think that shadows can be conceived as an image, or as something belonging to an object (Anderson B, Bach F; 2005). There is a need to see light as an entity in space for being able to give an explanation of the formation of shadows (Galili and Hazan 2000). 


\subsection{Vision}

Most of older students in study of Bendall, Goldberg et al. (1993) have the idea that the eye plays an active role while the object 'looked at' has a passive role

Students think that the eyes send out something making it possible for us to see. (Andersson, B. and F. Bach (2005), Palacios, J. and Al. (1989))

Heywood (2005) presents three categories of representations in students' reasoning how we can see an object. Visual representation where students' focus is on looking and seeing, the eye looking at the direction of the object. Light representation, where students' reasoning is concerned with where light is travelling. The third category is a dual representation, students' using both visual representation and light representation. Most of the student's misconceptions about vision have been founded in history.

Ibn-el Heythem has been the first who has revealed the function of eye and light. Ibn-el Heythem rejected the idea that the eye diffuses light. He also asserted that light beams come from the object and then to the eye.

\subsection{Image}

The students' difficulties with light as an entity in space is pointed out as a problem in image construction by (Heywood 2005).Image undergoes a deconstruction to a collection of points, each being transmitted by means of single light ray.

For Galili and Al (1993), the image construction is complex and one difficulty for students is to use multiple rays and point to point mapping simultaneously.

Concerning how students think about images in plane mirrors and lens, Goldberg \& McDermott (1986) indicated that a significant number of students believed that an observer can see an image only if it lies along his or her line of sight to the object, and that an image would be in different positions for different observers. They thought that the image of a rod placed in front of a mirror would move to the right if they moved to the left, they would be able to see more of themselves in a mirror by moving further away and the image of an object could be projected onto a screen without lens.

Goldberg and McDermott (1983) also reported that many students predicted that half the image would disappear when half of a lens was used to form the image.

The same misconceptions are shown by Galili, and Hazan (2000):

- The image stays in the mirror whether it is observed or not;

- The image moves from the object towards the mirror, where it stays;

- A half-lens produces a half-image. The rest of the image (rays) is blocked;

- When the screen moves towards or away from the lens the image will become bigger or smaller but remain sharp.

The students explain this by their understanding of geometric image construction rather than reasoning about cones of light being partially stopped by the cover

The misconceptions are listed in Table 1.

Table 1: Misconceptions

\begin{tabular}{|c|c|c|}
\hline Miscon & ception & Source \\
\hline$>$ & Each point on a luminous object emits light in one direction. & $\mathrm{HP}$ \\
\hline$>$ & Light travels further at night than during the day. & HP \\
\hline$>$ & $\begin{array}{l}\text { Light is not conceived as moving from one point to another with a finite } \\
\text { speed. }\end{array}$ & $\mathrm{H}$ \\
\hline$>$ & $\begin{array}{l}\text { Shadows can be conceived as an image, or as something belonging to an } \\
\text { object }\end{array}$ & G B \\
\hline$>$ & A shadow is a 'reflection' (reproduction) of an object. & G H \\
\hline$>$ & The stronger the source of light, give the bigger the shadow. & G H \\
\hline$>$ & The bigger the source of light, give the smaller the shadow. & G H \\
\hline$>$ & Objects are seen because they are bathed in light. & G \\
\hline$>$ & Light travels from the eyes to the object. & P C M \\
\hline & $\begin{array}{l}\text { We can see because light travels to your eyes and then from the eyes to } \\
\text { the object. }\end{array}$ & G \\
\hline$>$ & An individual's eyes see the shape of an object. & $\mathrm{E} \mathrm{HI}$ \\
\hline$>$ & Shiny objects reflect more light than dull objects. & E H I \\
\hline$>$ & Light is not necessary to see since we can see a little in a dark room. & B \\
\hline
\end{tabular}




\begin{tabular}{|c|c|}
\hline $\begin{array}{l}\text { Light always passes straight through transparent material (without } \\
\text { changing direction). } \\
\text { An observer can see more of his or her mirror image by moving further } \\
\text { back from the mirror. } \\
\text { The mirror image of an object is located on the surface of the mirror. } \\
\text { To be seen in a mirror, the object must be directly in front of the mirror or } \\
\text { in the line-of-sight from the observer to the mirror. } \\
\text { The image of an object placed to the side of a plane mirror does not exist } \\
\text { for any observer. } \\
\text { A plane mirror forms real images. } \\
\text { The convergent lens increases the speed of the light } \\
\text { Blocking part of the lens surface would block the corresponding part of } \\
\text { the image. } \\
\text { An image can be seen on the screen regardless of where the screen is } \\
\text { placed relative to a lens. } \\
\text { To see a larger image on the screen, the screen should be moved further } \\
\text { back. } \\
\text { The size of an image depends on the size (diameter) of the lens used to } \\
\text { form the image. } \\
\text { Images can be in two places. } \\
\text { Lenses are not necessary to form images. }\end{array}$ & $\begin{array}{l}\text { G M } \\
\text { G M } \\
\text { G M } \\
\text { G M } \\
\text { HB } \\
\text { P C M } \\
\text { P C M } \\
\text { G H } \\
\text { G H } \\
\text { G H } \\
\text { B } \\
F \\
F\end{array}$ \\
\hline
\end{tabular}

- BG: (Bendall, Goldberg 1993)

- G B: Galili, I., S. Bendall, (1993)

- G.H: Galili, I. and A. Hazan (2000)

- G: Guesne, E. (1985)

- G M: Goldberg F. M \& McDermott. L.C, (1986)

- H: Hapkiewicz, A. (1992).

- HB: Hubber B. (2005)

- B: Berthelsen, B. (1999)

- Eaton, Harding and Anderson (1985)

- F: Fetherstonhaugh. A. R, 1990

- PC M: Palacios, J. Cazorla, F. and Madrid, A.(1989)

\section{3, METHODOLOGY}

The participants in the study were 246 first year university students (age from 18 to 21). All of them had studied optics in secondary school.

From a survey of literature, it is found that most works on misconceptions about optics have employed interviews and/or open-ended questionnaires. Little research has used multiple choice tests. In our work, the paper multiple choice test was chosen as most appropriate for investigating a sample of 246 students and to diagnose students' misconceptions.

We utilized questions which had been used in previous studies of the light preconception (where their validity and effectiveness had been proved).

Our questionnaire comprised 12 questions, 10 of which are selected and partially modified from the studies investigating students' conception about vision, propagation of light, and imagery in reflection and refraction (Guesne, E. (1985), Viennot L. (1996), Fetherstonhaugh, (1990), Goldberg, F M. and McDermott.L. C, (1983), CHUNG-CHIH CHEN, (2002), ) and 2 of them (questions 2 and 3) redefined by the researchers (see table 2).

The test was taken by the students in a regular class environment, prior to the optics teaching for that year, under the condition of no time limit.

Table 2: Questionnaire description.

\begin{tabular}{|l|l|l|}
\hline Question & Item & Description \\
\hline- Q1 & Vision & $\begin{array}{l}\text {-Utilised the alternative frameworks for seeing identified by } \\
\text { Guesne 1985 }\end{array}$ \\
\hline
\end{tabular}




\begin{tabular}{|l|l|l|}
\hline -Q2, Q3and Q4 & $\begin{array}{l}\text { Propagation of } \\
\text { light }\end{array}$ & $\begin{array}{l}\text {-Using camera obscure } \\
\text {-A small triangular hole between light source and screen } \\
\text {-Obstacle between source of light and screen }\end{array}$ \\
-Q5 and Q6 & shadow & image by mirror \\
-Q7 and Q8 & -Observation the image of vase of flower in plan mirror \\
-Q9, Q10, Q11 & Image by lens \\
and Q12 & & -Image by a converged lens on a screen \\
\hline
\end{tabular}

\section{4, RESULTS AND DISCUSSION}

We present our results in four different sections: about conceptions around vision, propagation of light and image.

\subsection{Vision:}

Less than $50 \%(45 \%)$ have a scientific concept about vision: to be able to see the object, light coming from the light source to the object which reflects it and then light goes into the eye.

Significant numbers of students believed that light comes from eyes to the simple (26\%). This idea founded the Grek scientists. A similar number of students $(20 \%)$ thought that to see we don't need any material link between eyes and the objects observed. The objects are seen because they are bathed in light. This understanding of vision represents the initial stage in a succession of models of rising complexity that an individual adopts in the course of knowledge development (Gallili, 2000).

\subsection{Propagation of light}

In the following situation, we have asked student about what happen if there is vacuum (no air) inside of the camera obscure. The answers of this question are in table 3 ( see figure 1)

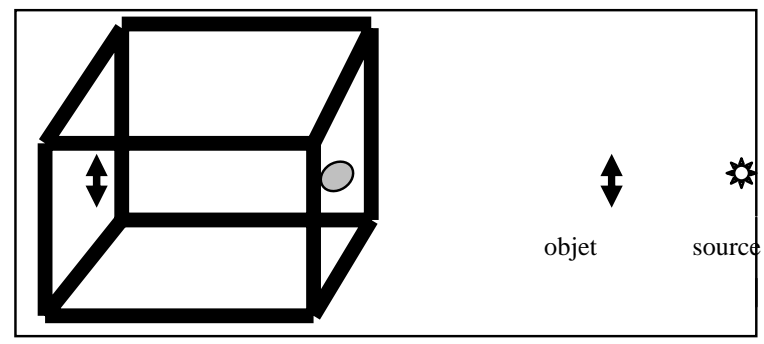

Figure1: Camera obscure

Table 3: Light propagation in the vacuum

\begin{tabular}{|l|l|}
\hline Answer & Percentage \\
\hline -no change & $27 \%$ \\
\hline - disappears & $44 \%$ \\
\hline - a spot of light & $21 \%$ \\
\hline - no answer & $\mathbf{8 \%}$ \\
\hline
\end{tabular}

Almost half of the questioned students (44\%) in Algerian university (before optics course) believe that the air is necessary for propagation of light. Also Sexena (1991), in its research to identify that Indian students conceptions in optics (16 are 20 years old), affirms that for many subjects the light cannot penetrate in a completely empty room (vacuum).

Significant number of students (21) thought that light propagates in only one direction (horizontal) under the conditions where the air does not exist.

In other questions ( $\mathrm{q} 3$ and $\mathrm{q} 4$ ) there is a mask with a small triangular hole between a small bulb and screen (Wosilait.K and McDermott 1998). The students are asked about the appearance of the image in the normal condition and under the condition where air does not exist.

The results obtained in this case confirm the presidents' results. Under the normal condition (presence of air) more than $48 \%$ give a good answer (triangle on the screen). But, when the air doesn't exist $36 \%$ of the students think that image disappears and approximately $21 \%$ of students believe we will see a small spot on the screen.

The new students misconception that we have found is that the light propagate in the horizontal direction when the air doesn't exist 


\subsection{Shadow}

In this item we ask students about the shadow of a ball (obstacle) between bulb and screen.

If the light source is very small, $37 \%$ of students think that the obstacle will blocks all the light and we will see a black screen. In the case where the source of light is very large (bigger than the obstacle), the screen becomes completely enlightened.

For $46 \%$ of the questioned students, the shadow exists on the screen in the case where the source of the light has the same dimension as the obstacle.

It seems that students holding the views corresponding to the Shadow Image scheme do not predict partial shadows (penumbra) (Gallili 2000).

\subsection{Image formation}

With an aim of knowing the students misconceptions about the formation of the images by reflection, we put questions about the image of the sludge which is on a table in front of a plane mirror.

Obviously, student's schemes of knowledge may not conform to scientific conceptions and may represent alternative interpretations of reflection. The students' misconceptions are listed in table 4 along with their percentage frequency of occurrence.

Table 4 Students' misconceptions

\begin{tabular}{|l|l|}
\hline Students response & Percentage \\
\hline -The image of the sludge in front of a plane mirror is on the mirror surface. & $43 \%$ \\
-The image of the sludge in front of a plane mirror is in front of mirror. & $35 \%$ \\
-The image of sludge placed in front of a mirror would move to the right if they moved to the left. & $41 \%$ \\
-There is no image if the sludge is not in front of mirror. & \\
-The image of sludge placed in front of a mirror would move to the right if the observant person & $31 \%$ \\
moved to the left. & $40 \%$ \\
-If de distance of the sludge from the mirror is increased the image would be smaller & $65 \%$ \\
\hline
\end{tabular}

Most of the student's misconceptions about the formation of image by using the convergent lens were shown in other studies.(MaCdermott,1996)

When the screen moves towards or away from the lens, many students $(31 \%)$ considered that the image will become bigger and sharp. A similar number of students $(32 \%)$ thought that the image given by lens will become smaller but remain sharp.

When half of a lens is covered, $45 \%$ of students believed that only half of the image of object appears on screen. The rest of the image is blocked. And significant number of students $(28 \%)$ thought that the image will have the half of dimension.

$22 \%$ of students thought that covering a centre of lens produces a half-image. But, for $43 \%$ of the questioned students, the image disappears. They think that the centre of the lens is responsible of image formation. In optics courses (or manual), we always found the light rays which passed from the centre of lens.

\section{5, CONCLUSION}

No change in students' misconceptions after 20 years of research concerning light and optical phenomena. Misconceptions, which have been found in earlier studies, were also determined in this study.

We also have found a new misconception. We can summarise these results as follows:

- $\quad$ Light propagates in the horizontal direction when the air doesn't exist.

- The centre of the lens is responsible of the image formation.

The misconceptions about optics phenomena are resistant to change with scientific knowledge ( Cigdem. SAHIN, 2008). Furthermore, this study offered to the teachers an opportunity to get acquainted with how they can study their pupils' preconceptions in optics as a part of their daily practice. 


\section{6, REFERENCES}

Andersson, B. \& Bach, F. (2005). On designing and evaluating teaching sequences taking geometrical optics as an example. Science Education, 89(2), 196-218.

Arons, A.B. (1990). A Guide to Introductory Physics Teaching. J. Wiley and Sons, New York.

Bendall, S., F. Goldberg, et al. (1993). Prospective elementary teachers' prior knowledge about light. Journal of Research in Science Teaching, 30(9), 1169-1187.

Berthelsen, B. (1999). Students Naïve Conceptions in Life Science. MSTA Journal, 44(1) (Spring'99), 13-19.

Bransford, J. D., Brown, A. L., \& Cocking, R. R. (Eds.). (1999). How people learn:Brain. mind, experience, and school. Washington, DC: National Academy Press.

CHUNG-CHIH CHEN. (2002). Developing a Two-Tier Diagnostic Instrument to Assess High School Students' Understanding - The Formation of Images by a Plane Mirror. Proc. Natl. Sci. Counc. ROC(D) Vol. 12, No. 3, 106-121

Çiğdem ŞAHIN, and Al .(2008). Students' understanding of light concepts primary school: A cross-age study. Asia-Pacific Forum on Science Learning and Teaching, Volume 9, Issue 1, Article 7

Driver, R. (1989). Students' Conceptions And The Learning Of Science. International Journal of Science Education, Vol. 11, Special Issue, 481-490.

Duit, R. (2002). Conceptual Change - Still a Powerful Frame for Improving Science Teaching and Learning. Proceedings of the Third European Symposium on Conceptual Change, June 26-28, Turku, Finland.

Duit, R. \& D. F. Treagus.t (2003). Conceptual change: A powerful framework for improving science teaching and learning. International Journal of Science Education 25(6): 671-688.

Duit, R. (2006). Bibliography. Students' alternative frameworks and science education STCSE., (http://www.ipn.uni-kiel.de/aktuell/stcse/stcse.html).

Eve Kikas1.(2003). University Students' Conceptions of Different Physical Phenomena. Journal of Adult Development, Vol. 10, No. 3, July

EATON, J., HARDING, T. AND ANDERSON, C.W. (1985) Light: A teaehin module Insitute for Research on Teaehing, Michigan State University, East Lansing, Michigan.

Fetherstonhaugh. A. R, MISCONCEPTIONS AND LIGHT: A CURRICULUM APPROACH Research in Science Education, 1990, 20, 105 - 113

Galili, I., S. Bendall, (1993). The effects of prior knowledge and instruction on understanding image formation. Journal of Research in Science Teaching 30(3): 271-301.

Galili, I. and A. Hazan (2000). Learners' knowledge in optics: interpretation, structure and analysis. International Journal of Science Education 22(1): 57-88.

Goldberg, F M. \& McDermott.L. C. (1983). Not all the wrong answers students give represent miseoneeptions. Examples from interview on geometrical optics. Proceedings of an International Seminar on Miseoneeptions in Scienee and Mathematics. Cornell University, Ithaea, New York, 335345.

Goldberg F. M \& McDermott. L.C. (1986). Student difficulties in understanding image formation by a plane mirror. Phys. Teach. $24,472-480$

Guesne, E. (1985)., Children's ideas in science (pp.10-32). Philadelphia, PA: Open University Press.

Hapkiewicz, A. (1992). Finding a List of Science Misconceptions. MSTA Newsletter, 38, $11-14$.

Heywood, D. S. (2005). Learning and Teaching About Light: Some pedagogic implications for initial teacher training. International Journal of Science Education 27(12), 1447-1475.

Hubber B. (2005), Asia-Pacific Forum on Science Learning and Teaching, Volume 6, Issue 1, Article 1, p.1

Langley, D., M. Ronen, et al. (1997). Light propagation and visual patterns: Preinstruction learners' conceptions. Journal of Research in Science Teaching 34(4), 399-424.

McDermott, and Al (1996). Physics by Inquiry Vols. 1 and II. New York: John Wiley \& Sons, Inc.

Mortimer, E. (1995). Conceptual change or conceptual profile change?. Science \& Education 4(3), 267-285. 
Palacios, J. Cazorla, F. and Madrid, A.(1989). Misconception of geometric optics and their association with relevant educational variables. International Journal of Science Education. Vol.11

$\mathrm{N}: 3,273-286$

Pfundt, H. \& R. Duit. (1994). Bibliography: Students' Alternative Frameworks and Science Education, Kiel:IPN.

Pınarbaşı T \& Canpolat N. (2003). Students' understanding of solutions chemistry concepts, J. Chem. Educ., 80, 1328-1332.

Sexena, A B. (1991). The understanding of the properties of lights by students in India. International Journal of Science Education. Vol.13 N:3,.283-289.

Smith and Al. (1993). Misconceptions reconceived: a constructivist analysis of knowledge in transition, J. Learn. Sci., 3, 115-163.

Stuart, R. (2007). Conceptual Change Through the Lens of Newtonian. Mechanics Science \& Education 16: 21-42

Viennot, L. (1979). Spontaneous Reasoning in Elementary Dynamics. European Journal of Science Education 1, 205-221.

Viennot L. (1996). Raisonner en physique, la part du sens commun, De Boeck.

Ygotsky, L. S. (1997). Thought and language (Rev. ed.). Cambridge, MA: MIT Press. (Original work published 1934)

Tao, P.-K. (2004). Developing understanding of image formation by lenses through collaborative learning mediated by multimedia computer-assisted learning programs. International Journal of Science Education 26(10): 1171-1197.

Tiberghien, A. (1997). Learning and teaching: Differentiation and relation. Research in Science Education V27 (3), 359-382. 